\title{
The location of the open-closed magnetic field line boundary in the dawn sector auroral ionosphere
}

\author{
J. A. Wild ${ }^{1}$, S. E. Milan ${ }^{1}$, C. J. Owen ${ }^{2}$, J. M. Bosqued ${ }^{3}$, M. Lester ${ }^{1}$, D. M. Wright ${ }^{1}$, H. Frey ${ }^{4}$, C. W. Carlson ${ }^{4}$, \\ A. N. Fazakerley ${ }^{2}$, and H. Rème ${ }^{3}$ \\ ${ }^{1}$ Department of Physics and Astronomy, University of Leicester, Leicester LE1 7RH, UK \\ ${ }^{2}$ Mullard Space Science Laboratory, University College London, Holmbury St. Mary, Dorking, Surrey RH5 6NT, UK \\ ${ }^{3}$ CESR/CNRS, 9 Avenue du Colonel Roche BP 4346, 31028 Toulouse, Cedex 4, France \\ ${ }^{4}$ Space Sciences Laboratory, University of California, Berkeley, USA
}

Received: 29 April 2004 - Revised: 8 June 2004 - Accepted: 21 June 2004 - Published: 3 November 2004

\begin{abstract}
As a measure of the degree of coupling between the solar wind-magnetosphere-ionosphere systems, the rate at which the size of the polar cap (the region corresponding to ionospheric termini of open magnetic flux tubes) varies is of prime importance. However, a reliable technique by which the extent of the polar cap might be routinely monitored has yet to be developed. Current techniques provide particularly ambiguous indications of the polar cap boundary in the dawn sector. We present a case study of spaceand ground-based observations of the dawn-sector auroral zone and attempt to determine the location of the polar cap boundary using multi-wavelength observations of the ultraviolet aurora (made by the IMAGE FUV imager), precipitating particle measurements (recorded by the FAST, DMSP, and Cluster 1 and 3 satellites), and SuperDARN HF radar observations of the ionospheric Doppler spectral width boundary. We conclude that in the dawn sector, during the interval presented, neither the poleward edge of the wideband auroral UV emission (140-180 nm) nor the Doppler spectral width boundary were trustworthy indicators of the polar cap boundary location, while narrow band UV emissions in the range 130-140 nm appear to be much more reliable.
\end{abstract}

Key words. Magnetosphere physics (auroral phenomena; magnetospheric configuration and dynamics polar cap phenomena)

\section{Introduction}

The concept of the "open" polar cap is a natural consequence of the open description of the magnetosphere proposed by Dungey (1961). Following reconnection at the dayside magnetopause, the terrestrial ends of newly-opened magnetic field lines remain anchored in the high-latitude ionosphere, inside the polar cap. Field lines are then dragged tailward by

Correspondence to: J. A. Wild

(j.wild@ion.le.ac.uk) the action of the solar wind in which the open "end" of the field line remains embedded. Although the exact motion of the field lines depends upon various factors, the orientation of the interplanetary magnetic field (IMF) is most significant. Magnetic field lines are added to the tail lobes before undergoing reconnection in the equatorial plane of the magnetotail and then returning to the dayside. The terrestrial footprints of the field lines move anti-sunward across the polar cap at high latitudes and sunward at lower latitudes. The demarcation between the closed field lines at lower latitudes and the first open magnetic field lines at higher latitudes defines a boundary enclosing the polar cap known as the "polar cap boundary" (PCB), "open-closed field line boundary" (OCFLB), or more simply, the "open-closed" boundary (OCB). Variations in the size of the polar cap correspond to the net rate of dayside and nightside magnetic reconnection. If the dayside reconnection rate is dominant, open flux will be added to the polar cap faster than it is closed by nightside reconnection; hence, the polar cap will expand (and vice versa), as described by Siscoe and Huang (1985) and Cowley and Lockwood $(1992 ; 1996)$. Therefore, the ability to instantaneously and globally determine the location of the OCB would make it possible to estimate the quantity of open magnetic flux within the polar cap and, by implication, estimate the degree of coupling and energy throughput between the solar wind, magnetosphere, and ionosphere systems. The development of a technique able to deliver such a capability is therefore of considerable importance and has been considered previously by many authors (e.g. Newell and Meng, 1988; Menk et al., 1992; Lockwood et al., 1993; Lewis et al., 1998; Rodger, 2000; Milan et al., 2003; Chisham and Freeman, 2003).

Unfortunately, and for a variety of reasons, the majority of the techniques developed to date are not globally applicable. For instance, in the cusp, the equatorward limit of energetic precipitating particles observed by low-altitude satellites has proven to be an effective proxy for the OCB (e.g. Newell and Meng, 1988), although the nature of satellite measurements implies that the boundary is sampled infrequently (ev- 
ery $\sim 100 \mathrm{~min}$ ) and at a single location during each overflight. Menk et al. (1992) employed ground magnetometer observations of ULF waves within the cusp; however, the relatively poor spatial resolution of this type of instrument may lead to significant ambiguities in the estimation of the boundary location.

A proxy frequently employed to identify the dayside OCB outside of the cusp is the poleward boundary of high energy (a few $\mathrm{keV}$ ) electron precipitation, usually associated with particles trapped on closed magnetic field lines (e.g. Evans and Stone, 1972). Poleward of the "trapping boundary", particles with typical magnetosheath energies $(<1 \mathrm{keV})$ or polar rain $(\sim 100 \mathrm{eV})$ are observed indicating magnetic field lines that have either recently been reconnected and are open to the magnetosheath and solar wind or which map into the open tail lobes and the solar wind. More recently, Lockwood (1997) and Oksavik et al. (2000) have suggested that magnetic field lines abutting on the equatorward side of this boundary on the dayside may in fact be open, an issue that remains unresolved; regardless, it is clear that field lines poleward of the trapping boundary must be of an open configuration. Moving to the nightside, the trapping boundary can no longer be employed as a proxy for the OCB since it marks the demarcation between dipolar and stretched magnetic field lines. In the nightside ionosphere the trapping boundary corresponds to the boundary between diffuse and more discrete aurora at higher latitudes (Galperin and Feldstein, 1991; Sergeev et al., 1993; Milan et al., 2003). In this case, the boundary between polar rain and harder precipitation associated with the discrete aurora is still useful, although the high energy particles are not necessarily trapped, but can be accelerated by the reconnection process that has resulted in the particles lying on closed field lines. Consequently, the boundary between energetic particles at lower latitudes and softer precipitation at higher latitudes corresponds to the OCB on both the dayside and nightside. Unfortunately, the scarcity of spacecraft observations highlighted above tends to hamper observations of the boundary over small temporal and spatial scales.

Ground-based measurements have made some progress in addressing this problem. In particular, high-frequency (HF) coherent-scatter radars, such as those of the Super Dual Auroral Radar Network (SuperDARN) (Greenwald et al., 1995), have been employed to monitor the OCB over large areas of the ionosphere. A boundary between low spectral width echoes at lower latitudes and high spectral width echoes at higher latitudes has been associated with the OCB on both the dayside (Baker et al., 1995) and nightside (Lester et al., 2001). Sometimes the backscattered power of the low spectral width echoes (corresponding to closed magnetic field lines) is insufficient to be detected by the radar system and only the high-width echoes are observed (Milan and Lester, 2001). In such cases, it is the equatorward edge of the high-width echoes that indicates the spectral width boundary (SWB) and the OCB. While on the dayside the SWB is an accepted proxy for the OCB, the same is not true at other local times. By drawing upon case studies, Lewis et al. (1997) and Dudeney et al. (1998) have suggested that the SWB observed by SuperDARN radars corresponds to the demarcation between the central plasma sheet and boundary plasma sheet (the so-called CPS/BPS boundary). Lester et al. (2001) proposed that the SWB can be employed as a proxy for the OCB in the pre-midnight sector; however, subsequent work by Woodfield et al. (2002) concluded that the relationship between the SWB and the OCB or CPS/BPS is a function of magnetic local time, and that the SWB corresponds to the BPS/CPS boundary in the 23:00-06:00 MLT sector. In a comprehensive statistical survey of SuperDARN spectral SWBs, Chisham and Freeman (2004a; 2004b) concluded that a SWB boundary is observed at all MLTs, although the nature of the boundary is dependent upon MLT. Furthermore, it was reported that in the 18:00-02:00 MLT sector, the OCB could be determined reliably using SuperDARN radar SWB observations. However, dawnward of this region, the relationship of the SWB between the OCB became less clear.

Since precipitating high-energy particles result in auroral luminosity, it is possible to utilise optical imagers to observe the OCB, assuming some relationship between the auroral oval and the OCB (e.g. Blanchard et al., 1995). Of course, space-based imagers have the chief advantage that they are capable of making global measurements of the aurora and are therefore well suited to the task of observing the OCB over many hours of local time (e.g. Frank and Craven, 1988; Milan et al., 2003). Previous comparisons between in-situ particle measurements and space-based observations of the UV aurora have revealed a discrepancy of a few degrees of latitude between the OCB and the poleward boundary of UV auroral emission (e.g. Kauristie at al., 1999; Baker et al., 2000), with the largest discrepancy in the 05:00 MLT sector (Carbary et al., 2003). We note that these studies have generally utilised wideband UV auroral imagery, typically corresponding to the Lyman-Birge-Hopfield (LBH) region of the UV spectrum ( $\sim 140-180 \mathrm{~nm})$.

While our overall understanding of the relationship of the OCB with the various observable proxies discussed above has improved dramatically in recent years, a routine and reliable technique that will reveal the location of the open/closed sepratrix at all magnetic local times has yet to be developed. In particular, several of the techniques are especially ambiguous in the post-midnight to dawn sector. In this paper, we will therefore investigate the correspondence between estimates of the OCB location in the dawn sector using (a) insitu particle measurements, (b) observations of UV emission made over multiple wavelength-bands, and (c) ground-based coherent-scatter radar measurements of the ionosphere during a case study based upon data from 8 December 2001.

\section{Instrumentation}

Upstream observations of the solar wind and IMF are provided by the MAG and SWEPAM instruments, respectively, on board the Advanced Composition Explorer (ACE) spacecraft (McComas et al., 1998; Smith et al., 1998; Stone et al., 
1998), located some $237 R_{E}$ upstream from the Earth during the interval of interest. The average propagation delay between field signatures appearing at the ACE spacecraft and their arrival at the subsolar magnetopause has been estimated to be $\sim 67$ min, using the technique described Khan and Cowley (1999).

Figure 1 presents the relative location of the Cluster spacecraft in the GSM $Y-Z$ plane at 14:15 UT on 8 December 2001. As presented here, the Cluster 1, 2, and 4 group lead the remaining spacecraft (Cluster 3 ) by approximately $12000 \mathrm{~km}$ as they pass through perigee and head poleward. The motion is approximately contained within the dawn-dusk meridian plane, with the four spacecraft spanning $\sim 3000 \mathrm{~km}$ in the GSM $X$ direction. This study will present particle observations from the Cluster 1 and 3 spacecraft as they move along similar trajectories (with Cluster 3 lagging behind Cluster 1 by approximately $45 \mathrm{~min}$ ), in order to examine the spatial and temporal variations in the boundary between open and closed magnetic field lines. More specifically, we will present observations of electrons in the $30 \mathrm{eV}-$ $20 \mathrm{keV}$ range made by the High Energy Electron Analyser (HEEA) sensor of the Plasma Electron And Current Experiment (PEACE) instrument on board Cluster 1 and 3 (Johnstone et al., 1997; Owen et al., 2001). Measurements of ions over a similar energy range are provided by the Hot Ion Analyser (HIA) sensor of the Cluster Ion Spectrometer (CIS) instrument (Rème et al., 1997, 2001).

Also indicated in Fig. 1 are the locations of the two other spacecraft included in this study, projected onto the GSM $Y-Z$ plane. Overpasses of the Defense Meteorological Satellite Program DMSP F13 (Hardy et al., 1984) and the Fast Auroral Snapshot (FAST) spacecraft (Carlson et al., 1998) are employed to provide measurements of precipitating auroral particles, allowing the location of the OCB to be identified.

Ionospheric flow measurements are provided by several Northern Hemisphere radars of the international SuperDARN array (Greenwald et al., 1995). Each radar scatters multi-pulse sequences of HF radio waves (commonly in the $10-14 \mathrm{MHz}$ range) from decametre scale electron density irregularities in the E- and F-region ionosphere. In addition to measuring the power of the backscattered echoes, Doppler spectra are computed from the autocorrelation function of the signals received from seventy-five $45-\mathrm{km}$ range gates along any given "beam" direction. From these spectra it is possible to determine the Doppler spectral width of the received echoes and line-of-sight (1-o-s) velocity of the scattering irregularities. During the interval presented in this study, each radar was operating in an identical mode, sounding 16 beams sequentially (dwelling on each beam direction for $3 \mathrm{~s}$ ), yielding a scan of the full field-of-view (f-o-v) approximately once per min. Figure 2 presents the fields-of-view of the three SuperDARN radars employed in this study in a magnetic latitude-magnetic local time coordinate system at 15:00 UT on 8 December 2001. Satellite-groundtracks corresponding to the 4 intervals of spacecraft observations employed in this study are indicated by arrowed lines. In each case, the mag-

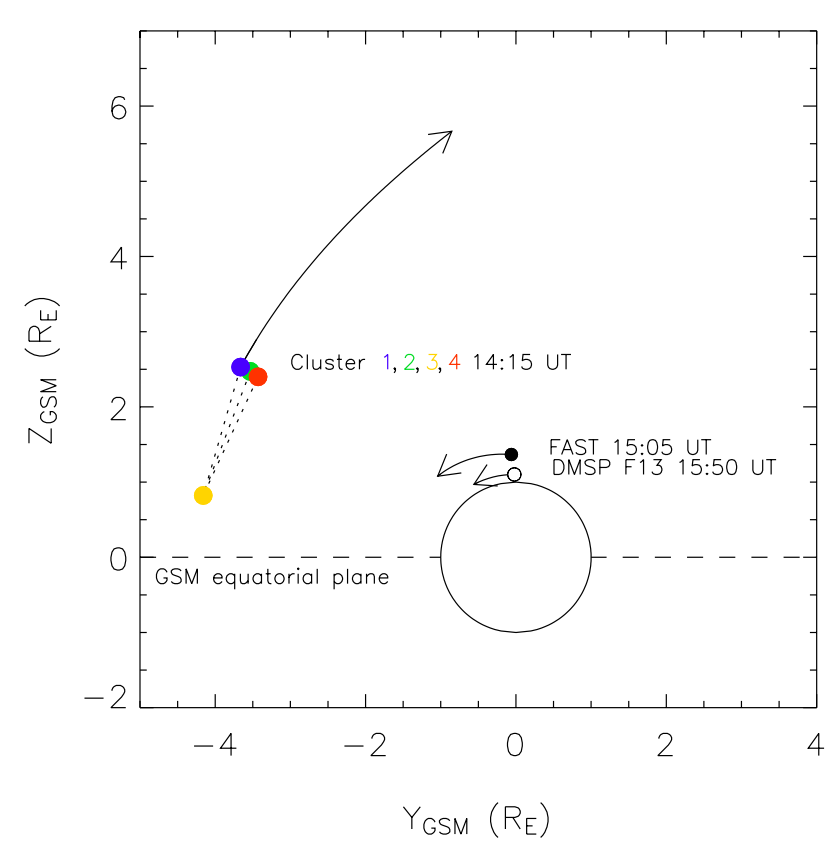

Fig. 1. The trajectories of the various spacecraft used in this paper, projected into the $Y-Z$ GSM plane. The positions of the Cluster quartet at 14:15 UT are indicated by filled dots (colour-coded as indicated) while the motion of Cluster 1 over the 75-min interval from which data is employed in this study is indicated by the solid arrowed line. Similarly, the location of the FAST spacecraft at 15:05 UT and the satellite's motion over the subsequent $20 \mathrm{~min}$ from which data are employed, are indicated by the filled black dot and solid arrowed line, respectively. Finally, the location of the DMSP F13 spacecraft at 15:50 UT and its trajectory during the 8-min interval from which data are exploited are indicated by the unfilled black circle and solid arrowed line.

netic field line footprint has been estimated using the Tsyganenko 1996 (T96) magnetic field model (Tsyganenko, 1995, 1996), parameterised by appropriately lagged solar wind and IMF observations.

Global observations of the auroral oval are provided by the Far UltraViolet (FUV) imager on board the Imager for Magnetopause-to-Aurora Global Exploration (IMAGE) spacecraft (Mende et al., 2000a, 2000b; Frey et al., 2001). The FUV instrument comprises three sensors, each sensor working simultaneously over different wavelength intervals and data from two of which are presented below. The Wideband Imaging Camera (WIC) has a passband of 140-180 nm with an almost negligible sensitivity below $140 \mathrm{~nm}$. It measures atmospheric and auroral emissions from the $\mathrm{N}_{2} \mathrm{LBH}-$ band, atomic NI lines, and small contributions from the OI $135.6 \mathrm{~nm}$ line, observing the aurora for between $5-10 \mathrm{~s}$ during every 2-min period. The Spectrographic Imager at $135.6 \mathrm{~nm}$ (SI-13) obtains images simultaneously in the 130 $140 \mathrm{~nm}$ wavelength interval corresponding to the doublet of oxygen $\mathrm{OI}$ emission (but also including some bands of $\mathrm{N}_{2}$ LBH emission). On 8 December 2001, FUV images of the Northern Hemisphere auroral oval were available from 15:00 UT onwards. 


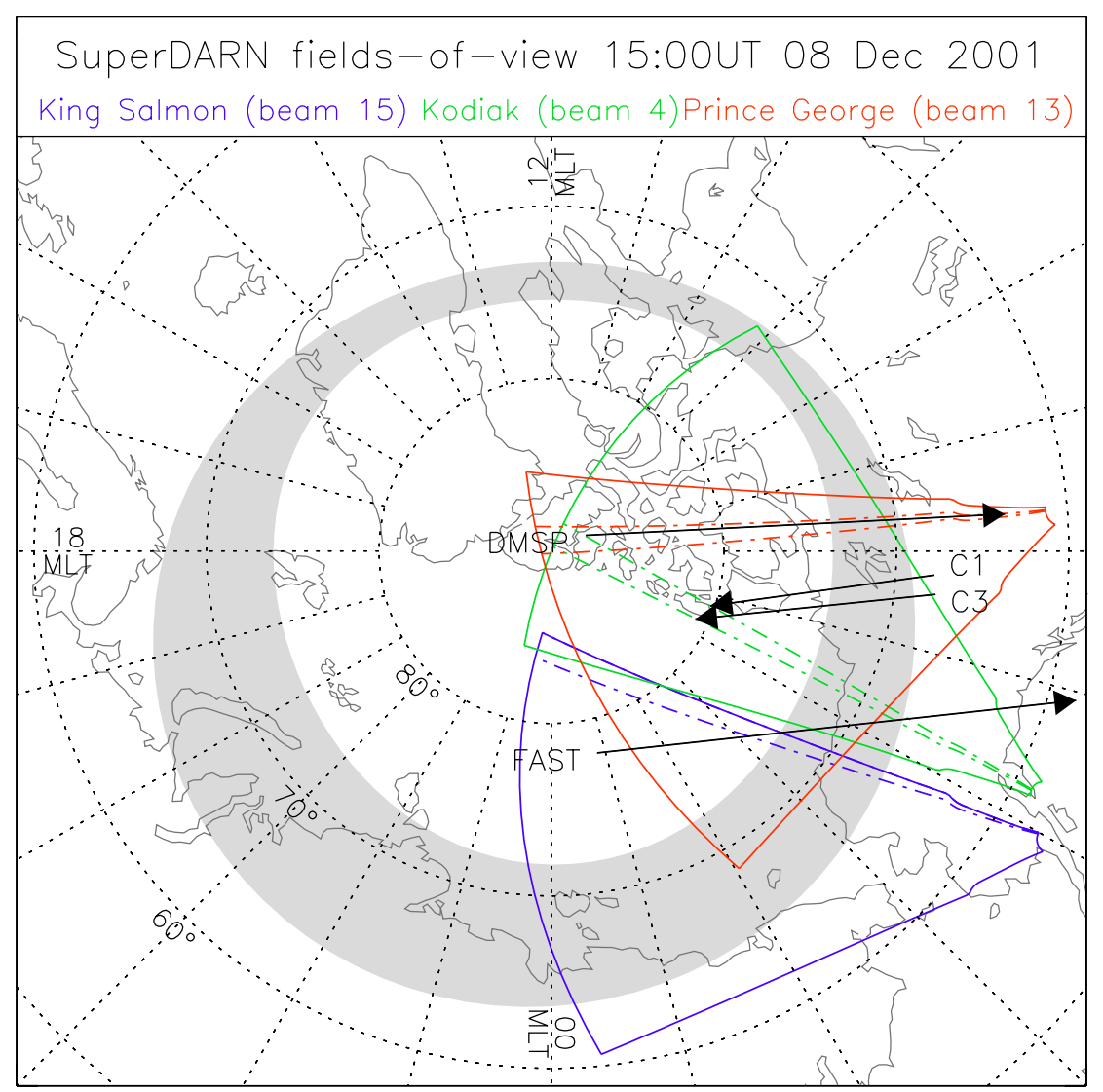

Fig. 2. The fields-of-view of the Northern Hemisphere SuperDARN radars employed in this study, presented in a MLT/magnetic latitude coordinate system at 15:00 UT on 8 December 2001. The overall fields-of-view and selected near-meridional beams of the King Salmon, Kodiak, and Prince George radars are colour-coded, as indicated in the key. The statistical location of the auroral oval (Feldstein and Starkov, 1967) for the prevailing geomagnetic conditions during the interval under study $\left(K_{P}=2\right)$ is indicated by the grey shading. Satellitegroundtracks corresponding to the 4 intervals of spacecraft observations discussed in the text are indicated by arrowed lines.

\section{Observations}

\subsection{Upstream solar wind and IMF conditions}

Figure 3 presents the ACE solar wind and IMF data for the interval 13:00-17:00 UT (lagged time) on 8 December 2001. Generally, the IMF was oriented southward $\left(B_{Z} \sim-3 \mathrm{nT}\right)$ and dawnward $\left(B_{Y} \sim-4 \mathrm{nT}\right)$, with a slight earthward component $\left(B_{X} \sim-2 \mathrm{nT}\right)$ until around 14:30 UT. During this interval, the radial solar radial wind speed was $\sim 420 \mathrm{~km} \mathrm{~s}^{-1}$, while the measured proton density was approximately $5 \mathrm{~cm}^{-3}$ (equivalent to a solar wind dynamic pressure of $\sim 2.0 \mathrm{nPa}$ ). At around 14:30 UT, the IMF reoriented to point northward $\left(B_{Z} \sim+2 \mathrm{nT}\right)$ and sunward $\left(B_{X} \sim+4 \mathrm{nT}\right)$, while the $B_{Y}$ component remained steady at $\sim-4 \mathrm{nT}$ (corresponding to a rotation of the IMF clock angle from $-135^{\circ}$ to $-75^{\circ}$ ). This reconfiguration of the IMF was accompanied by a $\sim 50 \%$ reduction in the solar wind proton density. Consequently, the solar wind dynamic pressure fell to $\sim 1.25 \mathrm{nPa}$, following the northward turning of the IMF.
3.2 Overview of ionospheric and magnetospheric dynamics

Ground-based magnetic field measurements from Canadiansector stations of the CANOPUS array (Rostoker et al., 1995) indicated dayside magnetic activity probably associated with the growth, expansion, and recovery phases of a magnetospheric substorm prior to the interval of interest. An in-depth investigation of the auroral and ionospheric dynamics associated with this event is beyond the scope of this study, and these data are therefore omitted for brevity. However, we note that substorm activity began at $\sim 12: 00$ UT (shortly after a southward turning of the IMF) and by $\sim 15: 00$ UT, following several periods of expansion/intensification, the recovery phase was sufficiently advanced such that the magnetic field conditions were similar to those observed prior to the substorm.

Figure 4 presents measurements of 1-o-s Doppler velocity and spectral width plotted as functions of magnetic latitude, universal time and MLT during the interval 14:15-16:15 UT on 8 December 2001, from a single, near-meridional beam of the King Salmon and Kodiak SuperDARN radars (indicated 

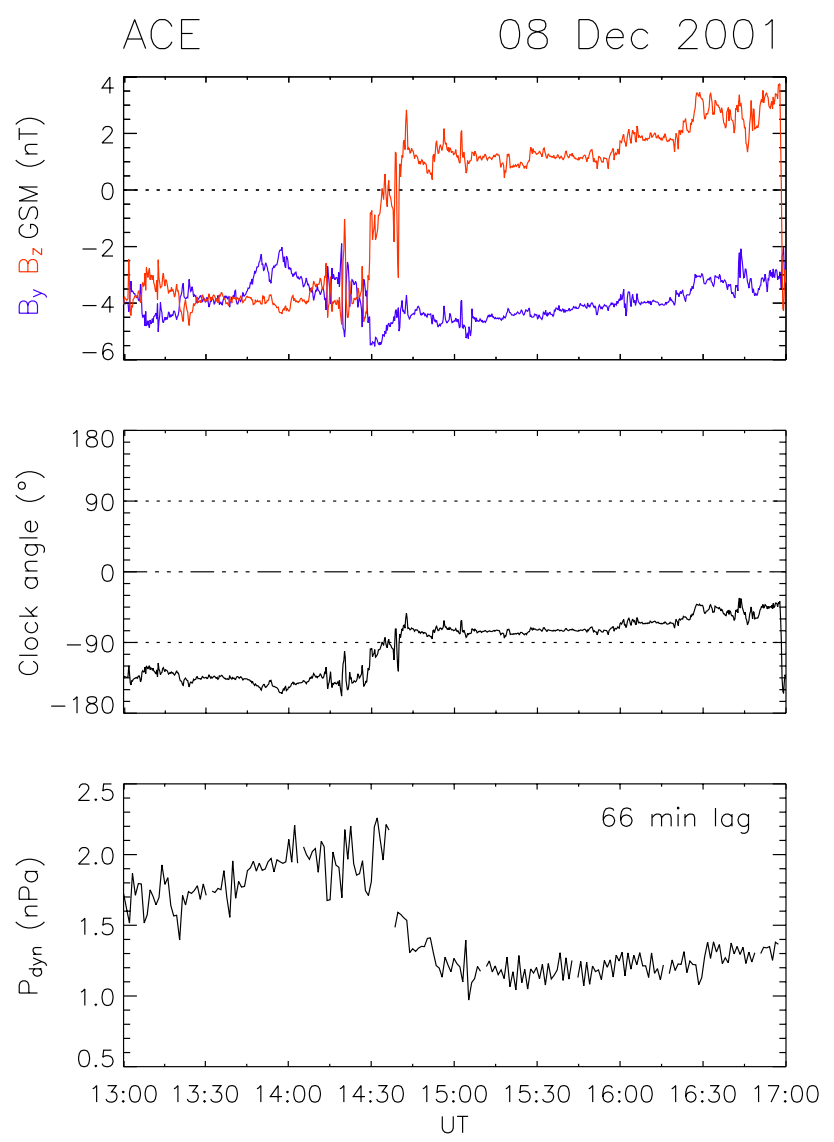

Fig. 3. Upstream solar wind and IMF observations from the Advanced Composition Explorer (ACE) spacecraft. The upper panel presents the GSM $Y$ and $Z$ components of the IMF (colour-coded as indicated), the centre panel presents the IMF clock angle in the GSM $Y-Z$ plane while the lower panel presents the solar wind dynamic pressure. Each time series has been lagged by $66 \mathrm{~min}$, in order to present the interplanetary conditions prevailing at the dayside subsolar magnetopause during the interval presented.

in Fig. 2). Where available, keograms of auroral luminosity measured by the IMAGE WIC and SI- 13 instruments at locations along these radar beams are also presented.

The ionospheric backscatter observed by King Salmon radar during the first half of the interval presented can broadly be divided into two distinct regions. At lower latitudes, the 1-o-s component of the ionospheric plasma drift velocity is low, generally $\leq 200 \mathrm{~m} \mathrm{~s}^{-1}$ toward the radar (i.e. equatorward), and associated with narrow $\left(\leq 50 \mathrm{~m} \mathrm{~s}^{-1}\right)$ Doppler spectral widths. Poleward of this region lies a band of ionospheric echoes characterised by high and variable Doppler spectral width (up to $\sim 500 \mathrm{~m} \mathrm{~s}^{-1}$ ) and an increased 1-o-s velocity component $\left(\geq 300 \mathrm{~m} \mathrm{~s}^{-1}\right)$. It is the demarcation between low spectral widths at lower latitudes and high spectral widths at higher latitudes that we refer to as the "spectral width boundary" (SWB), and which has previously been postulated as a proxy for the OCB. The boundary between echoes with Doppler spectral widths of less than and greater than $150 \mathrm{~m} \mathrm{~s}^{-1}$ is overlaid on the spectral width mea-
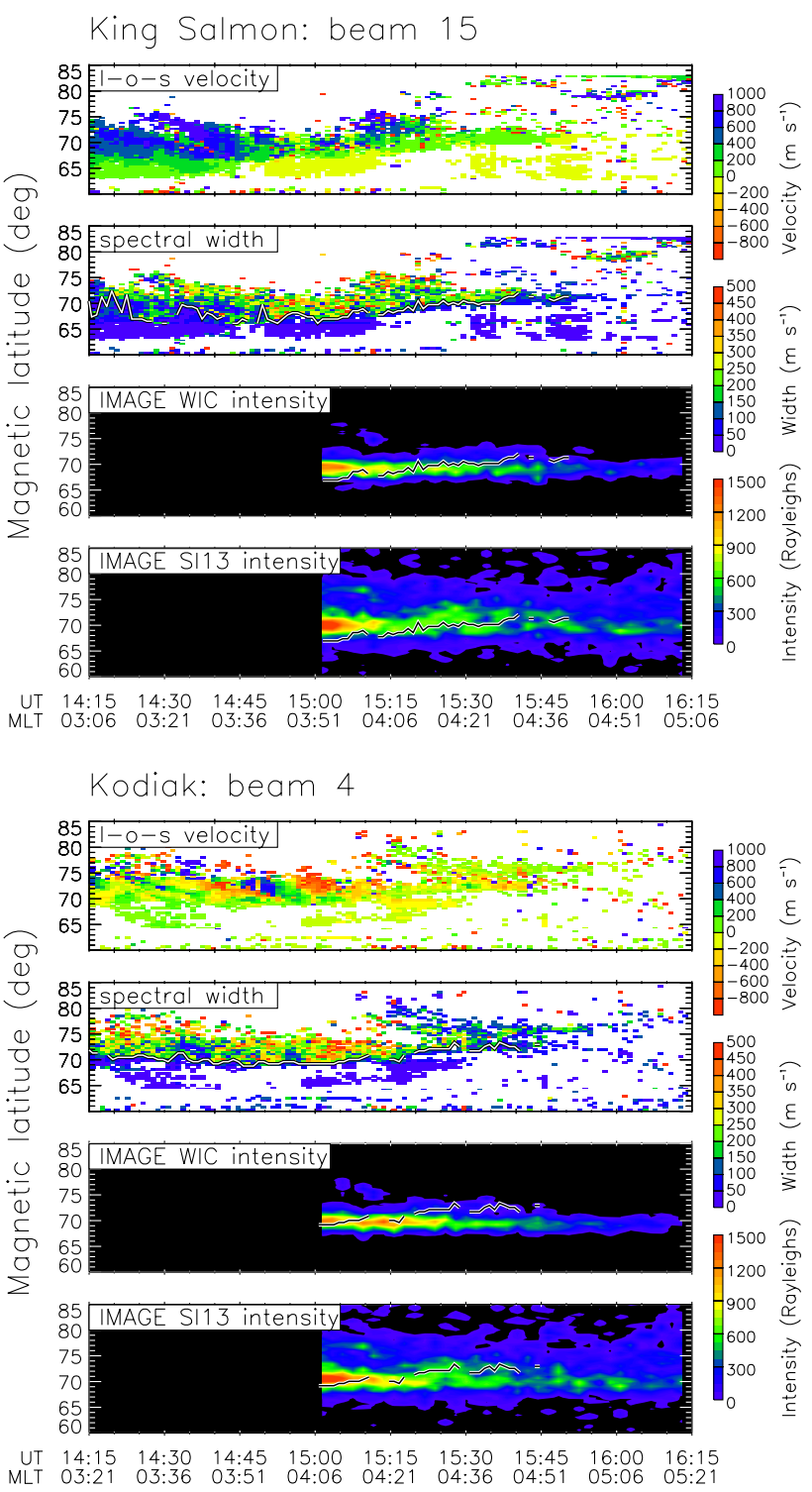

Fig. 4. Line-of-sight Doppler velocity and Doppler spectral width measurements from near-meridional beams of the King Salmon and Kodiak SuperDARN radars, presented as functions of magnetic latitude, universal time, and MLT. Where available, corresponding keograms of IMAGE WIC and IMAGE SI-13 measurements of auroral intensity along the radar beams are also presented. Each parameter is uniformly colour-coded as indicated. The Doppler spectral width boundary described in the text is overlaid on the spectral width, WIC and SI-13 measurements.

surements presented in Fig. 4 (the location and motion of the boundary being relatively insensitive to the exact threshold value chosen). Until $\sim 15: 15$ UT the equatorward boundary of the observed backscatter echoes was typically located at $63^{\circ}$ Mlat. However, the latitude of the poleward limit of the backscatter echoes and the SWB varied significantly. At $\sim 14: 45$ UT (some 10-15 min after the northward turning of the IMF), the boundary between high and low spectral width echoes began to migrate poleward at approximately $3^{\circ}$ Mlat 
per hour, after which the 1-o-s Doppler velocity in the equatorward (low spectral width) region was generally directed away from the radar. After 15:15 UT, backscattered echoes in the narrow spectral width region became increasingly sporadic, while the high width, high velocity echoes continued to be observed, albeit over an increasingly limited latitudinal range until approximately 16:00 UT.

The IMAGE FUV observations along beam 15 of the King Salmon radar (available from 15:00 UT onwards) indicate that the regions of UV auroral emission were broadlyspeaking collocated with the backscatter echoes observed by the SuperDARN radar. At 15:00 UT the region of brightest UV emission was centred at $\sim 70^{\circ}$ Mlat, just poleward of the Doppler velocity/spectral width boundary evident in the radar observations (for comparison the SWB determined from the radar data are overlaid on the FUV measurements). The wideband auroral emission observed in the main oval by the WIC sensor spanned $\sim 6^{\circ}$ Mlat, extending as far poleward as $\sim 73^{\circ}$ Mlat. The colour scale employed for the FUV data is common throughout this paper, spanning the range 11500 Rayleighs. As such the boundary of the auroral emission (i.e. the limit of the deepest blue shading) equates to a 1 Rayleigh threshold. During the interval presented, the luminosity generally decreased, while the latitudinal location of the peak auroral emission and poleward boundary tended to migrate poleward at approximately $1.5^{\circ}$ Mlat per hour (somewhat slower than the poleward motion observed in the case of the spectral width boundary), with weak auroral emissions observed until the end of the interval presented. The peak intensity in the SI-13 band was roughly collocated with the brightest WIC emission, although the low intensity emissions spanned a significantly wider range of magnetic latitudes $\left(\sim 60^{\circ}-85^{\circ}\right)$. Between 15:00-15:15 UT there was evidence in both channels of an equatorward drifting arc, initially located some $5^{\circ}$ poleward of the main auroral oval.

A spectral width boundary was also observed by the Kodiak radar, although in this case it was not associated with a clear demarcation in the observed l-o-s as Doppler velocity. As an aside, we note that one should exercise caution when monitoring the evolution of spectral width boundaries when the amount of backscattered echoes varies. During the interval presented in Fig. 4, the backscatter echoes observed after 14:15 UT in the narrow spectral width region equatorward of $\sim 69^{\circ}$ Mlat were generally intermittent. Obviously, this makes it difficult to identify a spectral width boundary per se (a problem discussed in detail by Chisham and Freeman, 2003). However, in this case, the $150 \mathrm{~m} \mathrm{~s}^{-1}$ SWB was located close to the equatorward edge of the observed radar backscatter. The flow observed at higher latitudes (in the high spectral width region) was generally directed poleward (up to $500 \mathrm{~m} \mathrm{~s}^{-1}$ away from the radar) but was punctuated by bursts of equatorward flow of similar magnitudes moving from higher $\left(\sim 74^{\circ}\right.$ Mlat) to lower $\left(\sim 69^{\circ}\right.$ Mlat) latitudes. By 15:15 UT, these strong and variable flows had subsided with the typical ionospheric plasma flow reduced to $\leq 200 \mathrm{~m} \mathrm{~s}^{-1}$ although, still variable in both magnitude and direction. As might be expected for meridional observations separated by
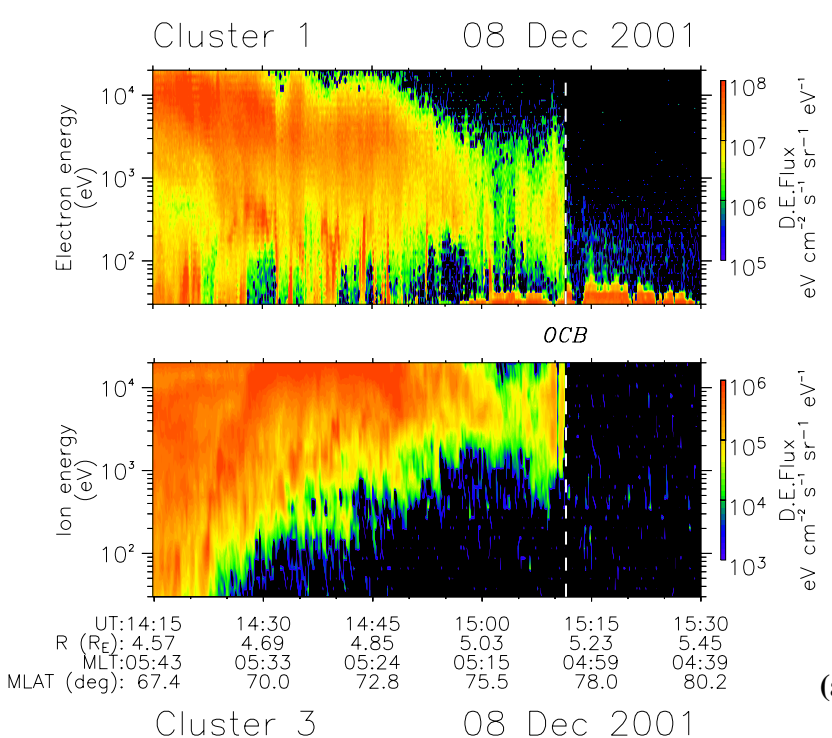

(a)
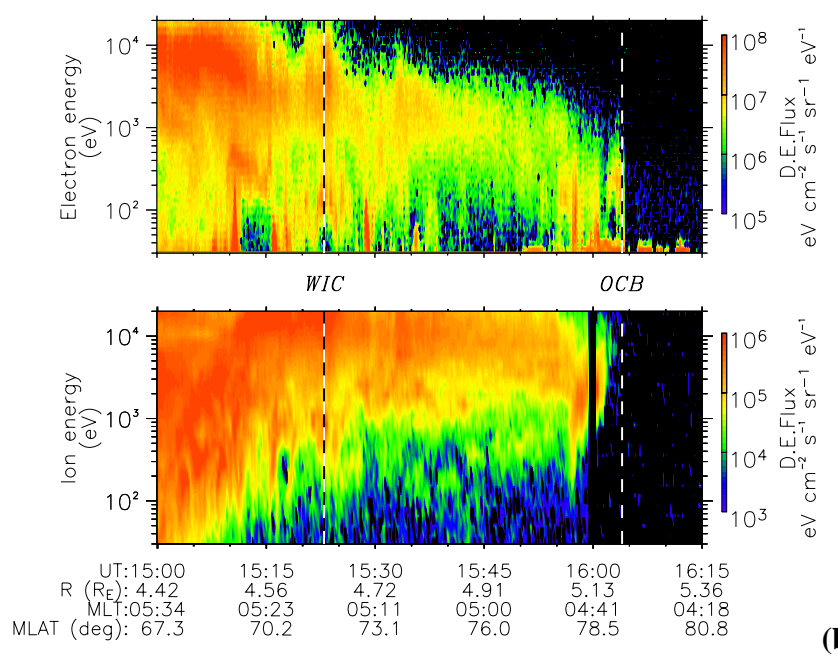

(b)

Fig. 5. Downward (field-parallel) moving electron and ion energytime spectrograms measured by the (a) Cluster 1 and (b) Cluster 3 spacecraft on 8 December 2001. The differential energy fluxes recorded by each instrument are colour-coded, as indicated in the colour bars. In addition to universal time, the observations at each spacecraft are presented as functions of the radial distance of the spacecraft from the centre of the Earth, the MLT of the spacecraft, and the magnetic latitude of its field line footprint. The time at which the spacecraft encountered the open-closed boundary (OCB) and, in the case if considering Cluster 3 only, the poleward boundary of the auroral emission observed by WIC, are indicated by dashed lines.

only $\sim 15$ min MLT, the IMAGE measurements along the King Salmon and Kodiak radar beams during these intervals are very similar. Once again, at the start of the interval presented, there is an approximate correspondence between the location of the SWB and the region of brightest auroral UV emission. As the interval progresses, the poleward migration of the Kodiak radar SWB outpaces the slight poleward motion of the auroral oval. 
3.3 Spacecraft observations of energetic particle boundaries

Energy-time spectrograms of downward (field-parallel) moving particles observed at the Cluster 1, Cluster 3, FAST, and DMSP F13 spacecraft during overflights of the auroral oval are presented in Figs. 5a and b, Fig. 6, and Fig. 7, respectively. In each pair of panels, electron and ion spectrograms are presented with common time scales which also indicate the radial position of the spacecraft from the centre of the Earth, the magnetic local time of the spacecraft and the magnetic latitude of the field line footprint traced using the T96 magnetic field model. In each case, field line traces have been parameterised by appropriate solar wind and IMF observations from the ACE spacecraft, taking into account the propagation delay discussed in Sect. 2.

Of these spacecraft, Cluster 1 was the first to cross the auroral zone, moving poleward on an outbound trajectory from perigee through the 05:00-06:00 MLT sector during the interval presented in Fig. 5a. As will be the case for all of the spacecraft observations presented here, we will not attempt to analyse the particle observations in detail. Instead, we shall present a broad overview of the interval and note the location at which energetic $(>10 \mathrm{keV})$ particles cease to be observed. At the beginning of the interval presented in Fig. 5a, Cluster 1 was located in the dawn-sector radiation belts, approximately $2.5 R_{E}$ above the GSM equatorial plane. In this region, the electron and ion sensors observed high particle fluxes across the full energy range of each instrument. Although the spectra presented here represent particles moving in the field parallel directions, inspection of all look directions for each instrument (not shown) indicated that the plasma population observed at this location and time was approximately isotropic. While these spectra indicate a great deal of structure (such as bursts of precipitating electrons in the $<1 \mathrm{keV}$ range and possible multiple approaches/encounters with the energetic particle boundary after 15:00 UT), it is clear from both the electron and ion fluxes presented in Fig. 5a that during this overflight of the dawn sector auroral region, the Cluster 1 spacecraft was measuring energetic particles typical of closed magnetic field lines until 15:12 UT. We note that the high fluxes of electrons with energies $<60 \mathrm{eV}$ observed after $\sim 14: 50$ UT are photoelectrons that have been emitted from the spacecraft and accelerated by the elevated spacecraft potential in regions of low background plasma density. As such, these electrons are ignored in the analysis presented here. At 15:12 UT, the magnetic footprint of the spacecraft traced to $100 \mathrm{~km}$ altitude above the surface of the Earth was located at $77.5^{\circ}$ Mlat and 05:04 MLT.

While Cluster 1 was traversing the dawn sector radiation belts and auroral oval, the FAST spacecraft was moving equatorward and dawnward over the nightside auroral oval. Figure 6 presents electron and ion spectrograms during a 20-min interval that includes the spacecraft's first encounter with particles of energies characteristic of closed magnetic field lines. (It should be noted that the interval
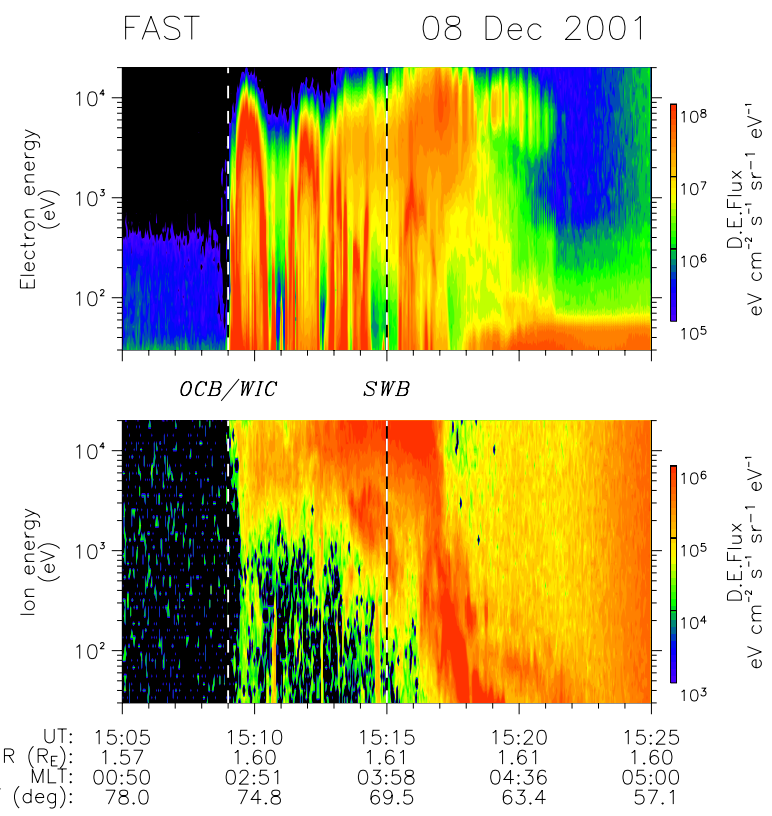

Fig. 6. Downward (field-parallel) moving electron and ion energytime spectrograms measured by the FAST spacecraft on 8 December 2001, presented exactly as in Fig. 6. The time at which the spacecraft encountered the open-closed boundary (OCB), the poleward boundary of auroral UV emission as observed by WIC and the latitude of the spectral width boundary (SWB) observed by SuperDARN are indicated by dash lines.

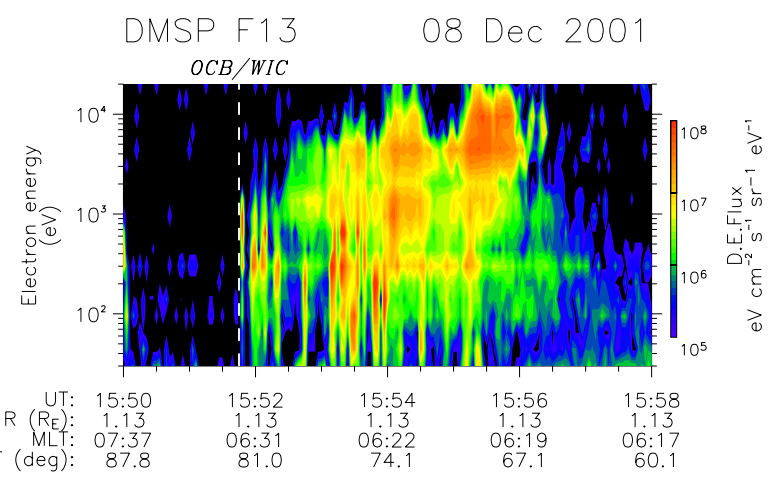

Fig. 7. Downward (field-parallel) moving electron energy-time spectrogram measured by the DMSP F13 spacecraft on 8 December 2001, presented exactly as in Fig. 6. The time at which the spacecraft encountered the open-closed boundary (OCB) and the poleward boundary of auroral UV emission as observed by WIC is indicated by a dashed line.

of FAST data is much shorter than the equivalent interval of Cluster data presented in Fig. 5a, since the FAST satellite orbits the Earth at an altitude of approximately $3800 \mathrm{~km}$ compared to $\sim 25000 \mathrm{~km}$ in the case of the Cluster spacecraft.) At 15:09 UT, when the footprint of the spacecraft was located at $75.7^{\circ}$ Mlat and 02:32 MLT, FAST observed the first of several "inverted V" signatures characteristic of large-scale acceleration of the auroral zone electron popula- 
tion (e.g. Frank and Ackerson, 1971; Burch, 1991; Newell, 2000). In addition, the first measurements of such electrons corresponded exactly to the first observations of high energy $(\sim 10 \mathrm{keV})$ ions.

The Cluster 3 spacecraft passed through perigee some 45 min after Cluster 1 and FAST, following an almost identical outbound trajectory to its companion spacecraft. Figure $5 \mathrm{~b}$ presents electron and ion energy-time spectrograms during a $75-\mathrm{min}$ period that approximately corresponds to the orbital path of Cluster 1 presented in Fig. 5a (for example, compare the magnetic local times and magnetic latitudes of the Cluster 1 and 3 spacecraft during the intervals presented). As was the case for Cluster 1, the particle fluxes observed at Cluster 3 were consistent with the motion of the spacecraft from the radiation belts, through energetic particle populations at higher latitudes and then into a void, in this case making the transition onto magnetic field lines that were not populated by high-energy plasma by $\sim 16: 04$ UT. Once again, there were indications of structure immediately prior to crossing the boundary from populated to empty field lines, and low-energy photoelectrons were observed straddling the boundary. However, in contrast with the Cluster 1 measurements, the poleward boundary of the ion and electron populations observed at Cluster 3 were not co-located (the electron population being observed for a minute or so after the final high energy ions). Nevertheless, by 16:04 UT Cluster 3 had moved into a region devoid of energetic particles, indicating that the boundary marking the transition from closed to open magnetic field lines (when mapped into the ionosphere) occurs at $\sim 79.3^{\circ}$ Mlat and 04:36 MLT.

Figure 7 presents electron and ion observations made by the DMSP F13 spacecraft during the final overflight to be used in this study. During the 8-min intervals shown in the figure, the spacecraft traversed the post-dawn sector auroral oval in an equatorward direction at an altitude of around $800 \mathrm{~km}$. The observations indicate that the spacecraft encountered the OCB (characterised here by the observation of $\sim \mathrm{keV}$ particles) a few seconds prior to 15:52 UT when the field line footprint was located at $81^{\circ}$ Mlat and 06:31 MLT. Ion observations from the DMSP F13 spacecraft have been omitted due to degradation of the low energy $(<1 \mathrm{keV})$ ion detectors on that satellite. Nevertheless, the onset of highenergy $(>1 \mathrm{keV})$ ion observations coincides almost exactly with the observation of electrons of similar energies.

\subsection{The location of the open/closed field line boundary}

Figure 8 synthesizes SuperDARN radar observations and measurements from the IMAGE FUV instrument between 15:00-16:00 UT in a magnetic local time-magnetic latitude coordinate system between 00:00-12:00 MLT; the figure is divided vertically into six triplets of panels, each separated by $\sim 10 \mathrm{~min}$. Within each trio, the upper panels $(\mathrm{a}-\mathrm{f})$ presents IMAGE WIC intensity measurements (it should be noted that the WIC measurements shown here do not extend equatorward of $60^{\circ} \mathrm{N}$ Mlat), the middle row (g-l) presents corresponding measurements from the SI-13 channel (that in this case extend to $50^{\circ} \mathrm{N}$ Mlat), while the lower panel of each column $(\mathrm{m}-\mathrm{r})$ shows near simultaneous $( \pm 30 \mathrm{~s})$ observations of Doppler spectral width of received ionospheric echoes, as measured by the SuperDARN radars discussed above. In all panels, the magnetic field line footprints of the various spacecraft discussed above are indicated by filled white or black dots. The radar-observed SWB, determined by a simple algorithm sensitive to the boundary between ionospheric backscatter echoes with Doppler spectral widths of less than and greater than $150 \mathrm{~m} \mathrm{~s}^{-1}$, is overlaid on each panel (where such a boundary was found to exist). Although intermediate IMAGE and SuperDARN observations are available between each of the six instances presented in Fig. 8, it is not practical to include all such measurements.

Figure 8a presents the first available FUV image during this interval, recorded at 15:01:23 UT. At this time, the brightest broad-band UV (WIC) emission occurs in the midnight-dawn sector. In the midnight sector, the remnants of the substorm auroral bulge extend to approximately $75^{\circ}$ Mlat and exhibit considerable intensity variations in the meridional direction, with peak intensity in excess of $1500 \mathrm{R}$. At increasing magnetic local times ( 03:00 MLT), auroral emission is observed extending to similar latitudes, albeit at considerably reduced intensity. The "main" auroral oval spans $\sim 6^{\circ}$ Mlat almost continuously over all local times presented in this figure, although intensity is diminished at increasing displacements from magnetic midnight. Contamination of the auroral signature is also apparent in the sunlit portion of the ionosphere. The simultaneous observations in the 130-140 nm wavelength band (SI-13) presented in Fig. 8g indicate a qualitatively similar distribution of auroral emission, however, the luminous region generally spans a much larger range of magnetic latitude $\left(\sim 15^{\circ}\right)$ and extends to $\sim 80^{\circ}$ Mlat with further, patchy emission at extreme high latitudes.

In order to further demonstrate the location of the Cluster 1 and 3 footprints with respect to the auroral emissions, Fig. 9 presents keograms of IMAGE WIC and SI-13 measurements along the 05:00 MLT meridian. Overlaid as functions of universal time are the magnetic latitudes of the Cluster 1 and 3 footpoints. By the time of the first image (15:02:23 UT, Fig. 8a), the footprint of the Cluster 1 spacecraft was already several degrees of magnetic latitude north of the poleward boundary of the dusk sector auroral oval observed by WIC, although still within the SI-13 emission (we recall that at this time the Cluster footpoints were moving poleward along an approximately meridional track at $\sim 05: 30$ MLT). However, at this time the footprint of Cluster 3 maps into the dawn sector auroral oval (according to both WIC and SI-13 images). Nevertheless, the Cluster observations of precipitating particles presented in Fig. 5 indicate that at the time of this auroral image, Cluster 1 and 3 were both engulfed in a particle population indicative of closed magnetic field lines. Although Cluster 1 was significantly $\left(\sim 10^{\circ}\right.$ Mlat $)$ poleward of Cluster 3 , it continued to observe energetic particles until around 15:12 UT. This time is indicated in Fig. 9 by a cross (labelled "OCB") and falls somewhere between Figs. $8 \mathrm{~b}$ and c. 

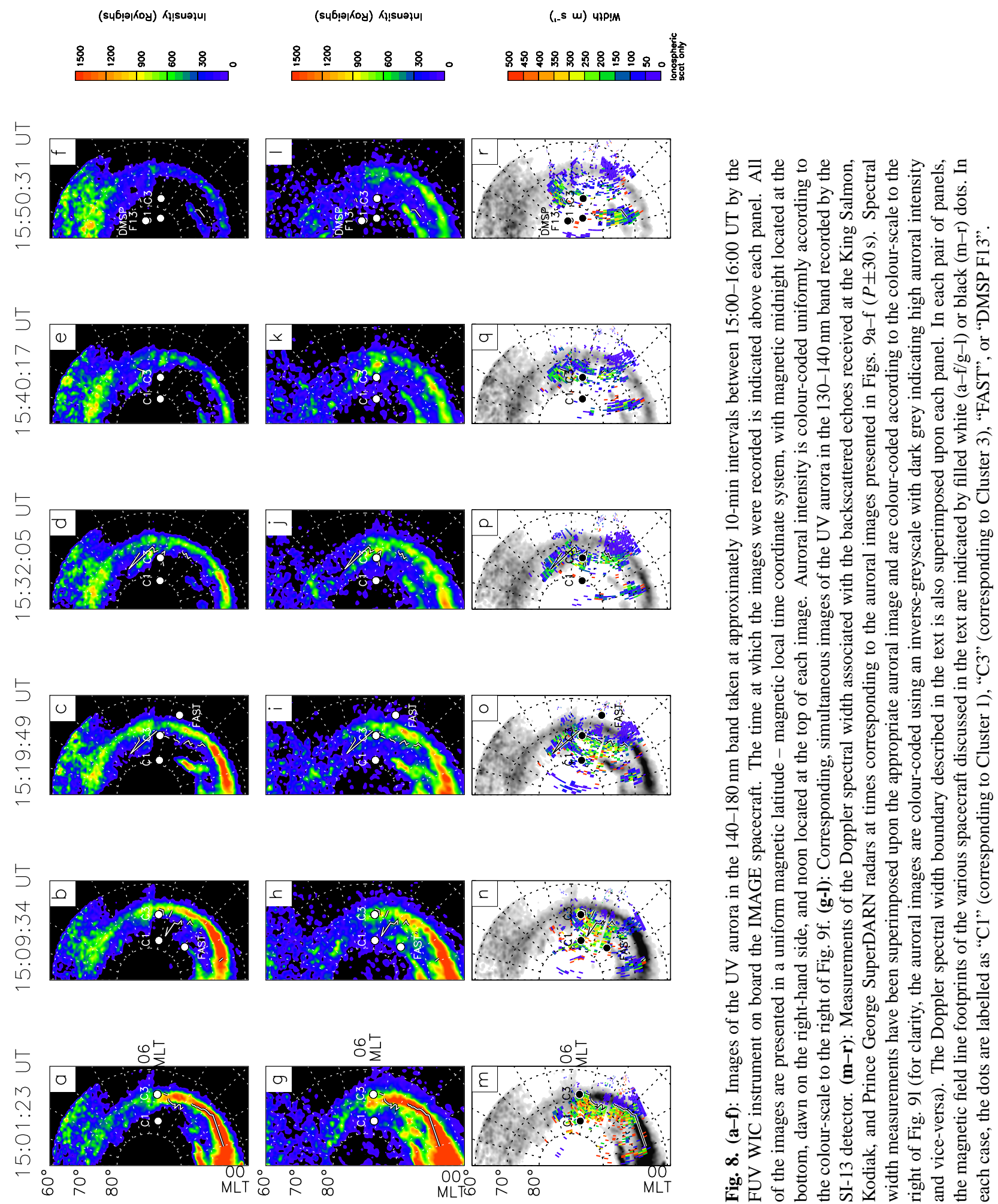


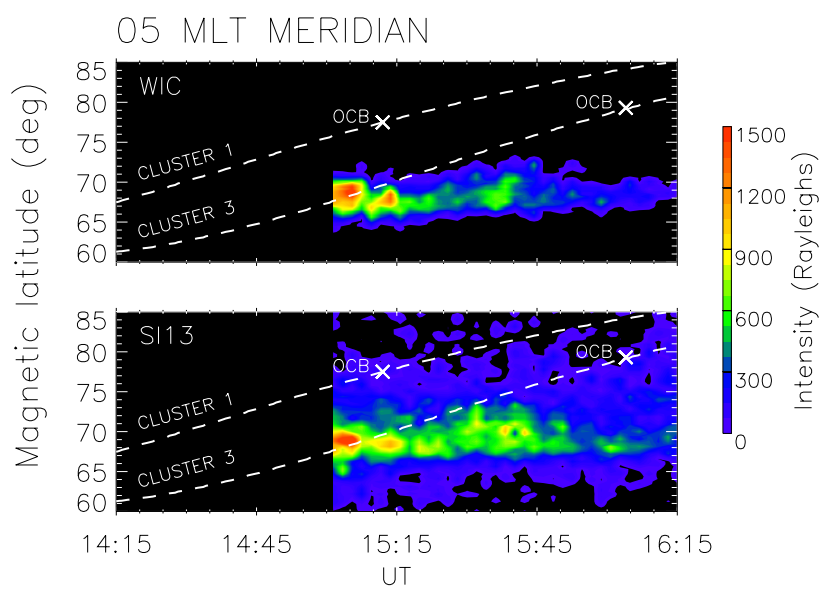

Fig. 9. Keograms of IMAGE FUC WIC (upper panel) and SI13 (lower panel) observations along the 05 MLT meridian during the interval 14:15-16:15 UT. Auroral intensity is colour-coded as a function magnetic latitude and universal time. Overlaid are the latitudinal position of the Cluster 1 and 3 magnetic footprints (dashed lines) and the times at which these satellites traversed the OCB as described in the text.

We note that as it passed through the energetic particle boundary at 15:12 UT, Cluster 1's magnetic footprint mapped to within $\sim 2^{\circ}$ Mlat of the poleward limit of 130 $140 \mathrm{~nm}$ (SI-13) emission.

In addition to spanning Cluster 1's penetration of the trapped particle boundary, Figs. $8 \mathrm{~b}$ and $\mathrm{c}$ indicate the equatorward motion of the FAST spacecraft as it traversed the auroral oval some $2 \mathrm{~h}$ of MLT westward of the Cluster spacecraft. FAST's encounter with an auroral region associated with closed magnetic field lines was accompanied by the simultaneous onset of the inverted $\mathrm{V}$ signatures in the electron spectrogram from the FAST electron detector presented in Fig. 6. The good agreement between these two data sets allows us to confidently define the latitudinal location of the OCB at a location some $3 \mathrm{~h}$ of MLT westward of the dawn meridian to be approximately $76^{\circ}$ Mlat, as well as confirming the validity of the field line mapping employed in this case.

Examination of Fig. 9 indicates that Cluster 3 mapped into the regions of brightest auroral emission until $\sim 15: 24$ UT (i.e. between Figs. $8 \mathrm{c}$ and d), at which time the spacecraft departed the region of broad-band UV (WIC) emission. Until this time, pitch angle distributions (not shown) indicated periods of electron anisotropy with net fluxes in either the upward or downward direction, consistent with the motion of the spacecraft through the spatially and temporally varying particle precipitation region above the auroral zone. Once Cluster 3 had traversed the broad-band UV (WIC) auroral oval, its footpoint remained within the region of 130-140 nm (SI-13) emission, where electron energies in excess of $1 \mathrm{keV}$ continued to be observed until the sharp cutoff at 16:04 UT. As indicated in Fig. 9, the cutoff roughly corresponded with Cluster 3's departure from the region of 130-140 nm (SI-13) emission. At this time, the footprint of Cluster 3 was displaced $\sim 7^{\circ}$ Mlat poleward of the high-latitude boundary of the auroral oval observed by WIC.

Considering now the SuperDARN spectral width observations presented in Fig. 8, at 15:01:23 (Fig. 8m), the spectral width boundary discussed in Sect. 3.2 was co-located with the poleward boundary of the brightest broad-band UV (WIC) emission in the 00:00-06:00 MLT sector with the narrow (high) spectral echoes corresponding to high (low) intensity auroral emissions. As has already been discussed, the auroral luminosity generally declined throughout the interval presented, as did the amount of radar echoes. However, the narrow-width/high-luminosity correspondence was observed, albeit to a lessening degree, throughout the interval. We also note that the gradual reduction of the spectral width of the echoes in the high spectral width region resulted in the SWB becoming less clear during the interval presented in Fig. 8. However, low spectral width echoes were usually observed at, or equatorward of, the brightest emissions observed by WIC and SI-13, with higher spectral width echoes extending poleward of this emission. Most importantly, the SWB was generally located at considerably lower latitude than the estimated position of the OCB, based on spacecraft particle observations.

\section{Discussion}

In the previous sections we have presented space- and ground-based observations of the ionosphere and near-Earth geospace environment during an interval in which the coupling of the terrestrial magnetosphere to the solar wind and interplanetary magnetic field varied considerably.

The first auroral observations available during this interval confirm that, in the midnight sector at least, recent substorm activity had closed a substantial quantity of magnetic flux. The remnants of the substorm auroral bulge (which we would expect to be comprised of closed flux tubes) extended to almost $80^{\circ}$ Mlat (Fig. 8a/g) and grew fainter over the following $\sim 60 \mathrm{~min}$. By $\sim 15: 50$ UT (Fig. $8 \mathrm{f} / \mathrm{l}$ ) the bulge had generally faded, although an azimuthally extended "arc", poleward of the main auroral oval, remained at $\sim 74^{\circ}$ Mlat for around another $10 \mathrm{~min}$.

Figure 10 presents a schematic comparison of the location of the dawn-sector OCB inferred from in-situ spacecraft observations of trapped energetic particles, broad-band UV (WIC) emissions, and 130-140 nm UV (SI-13) emissions. In the cases of FAST and DSMP, the OCB (defined by energetic particle observations), and the poleward boundaries of the UV emission observed by the WIC and SI- 13 sensors were collocated. As indicated by the Cluster observations, the poleward boundary of UV emissions observed by the WIC detector lay at much lower latitudes. Particle measurements from all 4 spacecraft indicate that the OCB is located near $78^{\circ} / 79^{\circ}$ Mlat, across the entire MLT coverage. The discrepancy between the location of the wideband UV emission and 
IMAGE WIC

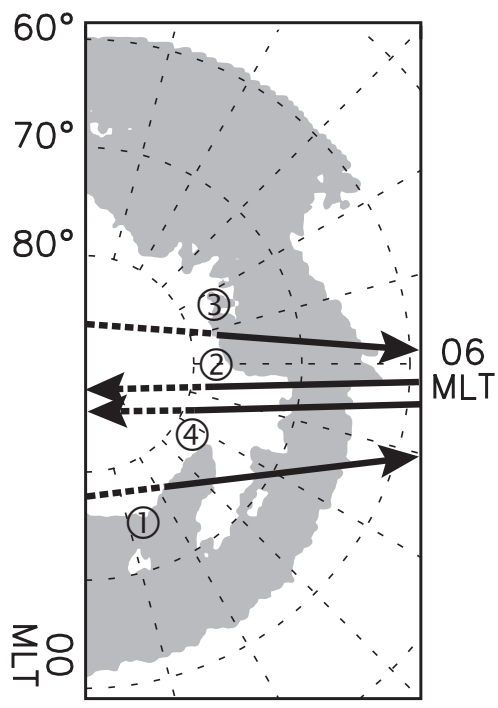

IMAGE SI-13

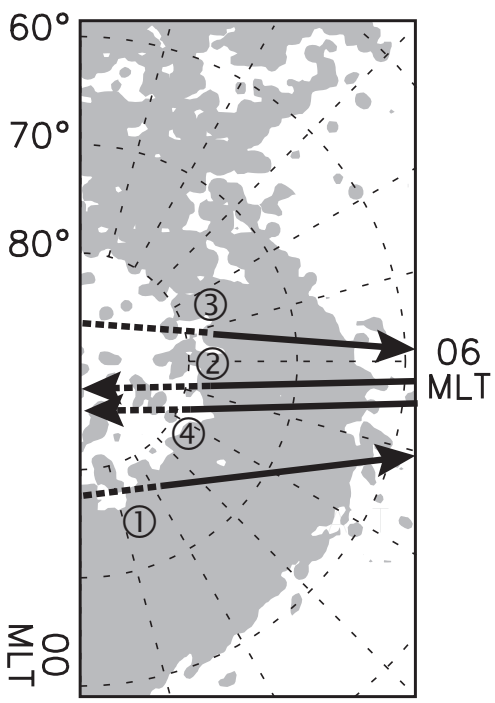

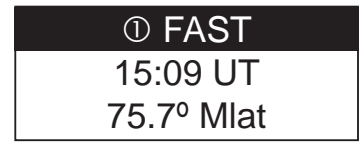

\begin{tabular}{|c|}
\hline (2) CLUSTER 1 \\
\hline $15: 12$ UT \\
$77.5^{\circ}$ Mlat \\
\hline
\end{tabular}

(3) DMSP F13

15:52 UT

$81.0^{\circ}$ Mlat

\begin{tabular}{c|} 
(4) CLUSTER 3 \\
\hline $16: 04$ UT \\
79.3ํㅡlat \\
\hline
\end{tabular}

Fig. 10. A schematic summary of the location of auroral emissions and the dawn-sector OCB (inferred spacecraft observations of trapped energetic particles) on 8 December 2001. The auroral overflights of the FAST, DMSP F13, and Cluster 1 and 3 spacecraft are presented in a Mlat-MLT coordinate system with each overflight indicated by a numbered heavy black line, arrowed to indicate the direction of motion of the spacecraft. The transition from dashed to solid line indicates the transition from open to closed magnetic field lines (i.e. the OCB). The universal time and magnetic latitude at which this took place for each spacecraft is indicated in the appropriate numbered box to the right of the figure. However, the regions in which auroral emissions were observed at 15:19:49 UT (corresponding to Fig. 8c/i) are indicated in Fig. 10 by the grey silhouettes.

the OCB in the dawn sector is due to a "hole" in the UV aurora observed by WIC.

As noted above, the Cluster spacecraft crossed the auroral oval at much greater altitudes than either FAST or DMSP $(\sim 25000 \mathrm{~km}$ compared to $\sim 1000 \mathrm{~km})$. As a first approximation, we may consider the FAST and DMSP observations as in-situ measurements of those particles that resulted in significant auroral emission. In contrast, the incongruity between the Cluster observations of the location of the OCB (at $\sim 25000 \mathrm{~km}$ altitude) and the poleward edge of the dawnsector auroral oval inevitably implies that the particles observed at Cluster were not able to deliver a sufficient energy flux to auroral altitudes, either because most of the particles mirrored prior to reaching auroral altitude or because the precipitating particles were insufficiently energetic to stimulate UV emission (or, more likely, a combination of these factors). As an aside, we note that the magnetic field predicted by the T96 model at the location of the Cluster satellites was in excellent agreement with the magnetic field observed at Cluster 1 and 3 (not shown) during the intervals presented in this paper: we are therefore confident in the T96 magnetic field line mapping employed throughout in order to estimate the ionospheric footprint of the Cluster spacecraft orbiting at $\sim 25000 \mathrm{~km}$ altitude.

In order to further investigate the precipitation of particles in the region poleward of the auroral oval observed by the IMAGE FUV WIC sensor but equatorward of (a) the OCB observed by Cluster 1 and 3 and (b) the poleward boundary of 130-140 nm (SI-13) UV emission, we shall compare the intensity of the emissions measured by WIC with the equivalent images recorded by the SI-13 channel of the IMAGE FUV instrument. Since the atmospheric $\mathrm{O}_{2}$ absorption varies in the wavelength intervals over which the WIC and SI-13 detectors operate, the ratio of the WIC and SI-13 measurements is sensitive to the depth at which the precipitating particles cause some excitation. Consequently, the ratio of the WIC and SI-13 measurements is sensitive to the average energy of the precipitating particles; for instance, large SI13 to WIC intensity ratios signify soft electron precipitation (Hubert et al., 2002). Clearly, the ratio of SI-13 to WIC intensity was highest outside of the main auroral oval where the WIC intensities fall to zero. As has been noted above, the "dark" polar cap was significant smaller in area when viewed in the SI-13 channel than with WIC. For example, at 15:50:31 UT (Figs. 8f, 1 and r), the Cluster 3 spacecraft was $\sim 6^{\circ}$ poleward of the auroral oval observed by WIC, but still mapped into auroral emission measured by the SI-13 detector, suggesting that the particles responsible for this auroral excitation (i.e. the subset of particles presented in Fig. 5b that lay within the loss cone) were of relatively low energies. This interpretation is confirmed by a comparison of the electron energy flux in the downward-going look direction observed at Cluster 3 and the auroral intensity at the spacecraft's magnetic footprint. Such a comparison is presented in Fig. 11. This figure clearly illustrates the relationship between the energy flux associated with precipitating hard electrons (in this case $>5 \mathrm{keV}$ ) and the wideband UV emission observed by WIC during the first $30 \mathrm{~min}$ of the interval 

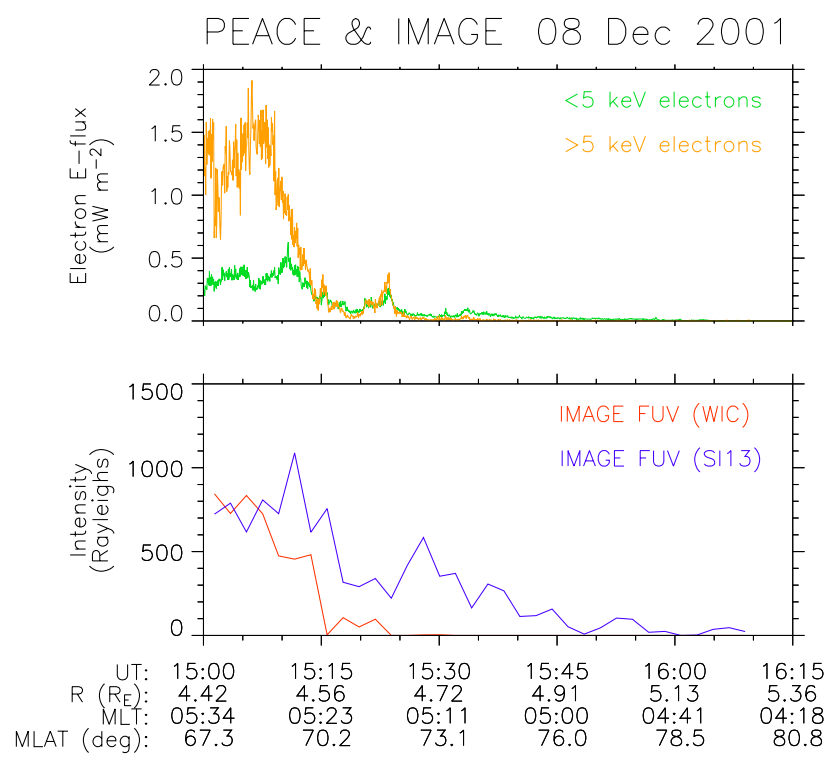

Fig. 11. A comparison between the energy flux associated with downward precipitating electrons observed at Cluster 3 (upper panel) and the simultaneous auroral intensity at the field line footprint of the spacecraft, as observed by IMAGE (lower panel). The estimated energy flux at Cluster 3 is divided into the contributions from electrons with energy less than, and greater than $5 \mathrm{keV}$, represented by the green and yellow lines, respectively. The auroral intensity at the magnetic footprint of Cluster 3 measured by the WIC and SI-13 FUV sensors are indicated by the red and indigo lines, respectively.

presented. By $\sim 15: 24$ UT Cluster 3 had traversed the main auroral oval observed by WIC, however, significant auroral emission was observed at the footprint of Cluster 3 by the SI13 detector for over $40 \mathrm{~min}$ after this time. The implication that this excitation was a consequence of "soft" electron precipitation is supported by the relative energy fluxes of electrons above and below $5 \mathrm{keV}$. Following the departure from the oval observed by WIC, the energy fluxes of electrons with energies $<5 \mathrm{keV}$, although small, exceeded the energy fluxes of higher energy electrons until the spacecraft crossed the OCB at $\sim 16: 04$ UT (some auroral luminosity is evident after this time, most likely a consequence of the significantly lower temporal resolution of the IMAGE FUV sensors when compared to the Cluster PEACE instrument). Consequently, we suggest that the poleward boundary of wideband UV auroral emission (to which the WIC instrument is sensitive) is, in this case, an unreliable indicator of the OCB location. However, the efficacy of this proxy appears to be highly variable over relatively small regions. For instance, we note that the boundaries of auroral luminosity observed by the WIC and SI-13 sensors were approximately co-located (at least to within $1-2^{\circ}$ of latitude) in the MLT sectors traversed by the FAST and DMSP spacecraft during this case study, as indicated in Fig. 10. Therefore, in order to confidently estimate the location of the OCB, it seems that it is necessary to consider the location of the poleward boundary of the auroral oval when viewed in more than a single wavelength passband.

As discussed in Sect. 1, the demarcation between regions corresponding to high and low Doppler spectral width echoes observed by HF radars has previously been employed as a proxy for the OCB. During the interval presented above, a spectral width boundary was clearly apparent for several hours and, where overlapping auroral images were available, this boundary appeared to coincide with the region of brightest auroral luminosity. The FAST passage over the predawn sector auroral oval crossed this spectral width boundary at $\sim 15: 14 \mathrm{UT}$, some $5 \mathrm{~min}$ after crossing the co-located OCB/auroral oval boundary. Therefore, the HF radar spectral width boundary does not in this case correspond to the OCB. During this example, there were indications of intense and structured electron precipitation as the spacecraft passed over the spectral width boundary (Fig. 7), suggesting that this boundary may be related to variations in the electric field imposed upon the ionosphere in that region or localised gradients in the ionospheric conductivity. Unfortunately, reliable measurements of the electric field at the FAST spacecraft, which may have yielded further insight into this effect, were not available during this interval. Nevertheless, throughout the interval presented a significant and persistent latitudinal separation was observed between the coherent scatter radar spectral width boundary and the inferred location of the open-closed magnetic field lines boundary.

\section{Summary}

By employing space- and ground-based observations of the dawn-sector auroral zone on 8 December 2001, we have compared the locations of the open/closed field line boundary, the poleward boundary of the auroral oval when viewed over two UV wavelength bands, and a Doppler spectral width boundary apparent in HF coherent scatter radar echoes.

Images of the ultraviolet aurora from the IMAGE FUV instrument were available at 2-min intervals from 15:00 UT on this day. During the interval 15:00-16:00 UT, the nightside UV aurora observed by the IMAGE FUV WIC sensor was dominated by the fading remnants of a pre-existing substorm auroral bulge which extended to $\sim 75^{\circ}$ Mlat and approximately spanned 00:00-03:00 MLT, while in the 04:0006:00 MLT sector, the aurora was generally not observed poleward of $\sim 71^{\circ}$ Mlat. This is in contrast to the IMAGE FUV SI-13 observations, which reveal a significantly broader auroral oval at all magnetic local times, generally extending to $\sim 80^{\circ}$ Mlat. Where good quality simultaneous measurements were available, the SuperDARN spectral width boundary generally coincided with the poleward limit of the most intense ultraviolet auroral emission (although this was significantly equatorward of the higher latitude auroral luminosity). Spacecraft observations of trapped, energetic $(\sim \mathrm{keV})$ particles from 4 overflights of the auroral oval imaged by the IMAGE FUV instrument during this interval have been employed to deduce the latitudinal location of the OCB be- 
tween 02:00-07:00 MLT. Where the wideband (WIC) aurora extended to high ( $>75^{\circ}$ Mlat) latitudes (i.e. at local times earlier than 04:00 MLT and later than 06:00 MLT), an excellent correspondence between the location of the OCB (inferred from FAST and DMSP F13 observations) and the poleward boundary of the wideband UV auroral oval was observed. No such correspondence was observed between 04:00-06:00 MLT. In this sector, the Cluster spacecraft were situated on closed magnetic field lines long after crossing the poleward boundary of the wideband UV auroral oval (as indicated in Fig. 10). However, examination of simultaneous images recorded by the IMAGE FUV SI-13 sensor (which is sensitive to a greatly reduced wavelength interval) indicates that auroral emissions extend to latitudes significantly poleward of the main oval observed by WIC and that these emissions were most likely a consequence of relatively soft electron precipitation ( $\sim$ few $\mathrm{keV})$. This interpretation is supported by estimates of the energy flux of downward-moving electrons observed at higher altitudes above the emission region by the Cluster 3 spacecraft.

The degree of correspondence between the location of the OCB and the poleward edge of the wideband UV auroral oval in the dawn sector therefore appears to be highly variable over a limited range ( $\sim$ few hours) of magnetic local times. Although the reason for this variability is not wholly clear from the data presented, the sensitivity of the WIC detector is almost certainly a contributing factor. Our findings suggest that in this case at least, the poleward boundary of the wideband UV auroral oval observed by WIC was an inferior proxy for the OCB compared to the 130-140 nm emission observed by the SI-13 instrument. We therefore suggest that future studies should exercise caution when employing wideband global auroral images, in order to determine the size of the polar cap bounded by the OCB. Furthermore, we confirm that HF radar spectral width boundaries in the dawn sector do not necessarily correspond to the OCB, as they appear to do so on the dayside and closer to midnight (Chisham and Freeman, 2004a, 2004b). Care should be taken in the interpretation of their physical significance. As yet, it is unclear precisely what geophysical structure these boundaries represent and this is likely to be the focus of future research.

Acknowledgements. The authors would like to thank the PIs of the SuperDARN radars from which data have been presented, namely B. Bristow (Kodiak), T. Kikuchi (King Salmon) and G. Sofko (Prince George). The DMSP particle detectors were designed by D. Hardy of AFRL, and data obtained from JHU/APL. We thank D. Hardy, F. Rich, and P. Newell for its use. Many thanks also to N. Ness and the ACE Science Center for providing the solar wind and IMF observations presented here. The CANOPUS array was deployed, and is maintained and operated by the Canadian Space Agency who provided the magnetometer data employed in this paper. For the Cluster fluxgate magnetometer (FGM) data employed during the preparation of this paper, we thank A. Balogh and the FGM team. Finally, we thank S. Cowley, T. Yeoman, and E. Bunce for their many helpful discussions during the writing of this paper. During the course of this study J. Wild was supported by PPARC grant number PPA/G/O/2001/0014 while D. Wright was supported by PPARC advanced postdoctoral fellowship number PPA/A/S/2001/00433.

Topical Editor T. Pulkkinen thanks two referees for their help in evaluating this paper.

\section{References}

Baker, K. B., Dudeney, J. R., Greenwald, R. A., Pinnock, M., Newell, P. T., Rodger, A. S., Mattin, N., and Meng, C.-I.: HF radar signatures of the cusp and low-latitude boundary layer, J. Geophys. Res., 100, 7671-7695, 1995.

Baker, J. B., Clauer, C. R., Ridley, A. J., Papitashvili, V. O., Brittnacher, M. J., and Newell, P. T.: The nightside poleward boundary of the auroral oval as seen by DMSP and the Ultraviolet Imager, J. Geophys. Res., 105, 21 267-21 280, 2000.

Blanchard, G. T., Lyons, L. R., Samson, J. C., and Rich, F. J.: Locating the polar cap boundary from observations of $6300 \AA$ auroral emission, J. Geophys. Res., 100, 7855-7862, 1995.

Burch, J. L.: Diagnosis of auroral acceleration mechanisms by particle measurement, in: Auroral Physics, edited by Meng, C.-I., Rycroft, M. J., and Frank, L. A., Cambridge Univ. Press, New York, 1991.

Carbury, J. F., Sortirelis, T., Newell, P. T., and Meng, C.-I.: Auroral boundary correlations between UVI and DMSP, J. Geophys. Res., 108(A1), 1018, doi:10.1029/2002JA009378, 2003.

Carlson, C. W., Pfaff, R. F., and Watzin, J. G.: The Fast Auroral Snapshot mission, Geophys. Res. Lett., 25, 2013-2016, 1998.

Chisham, G. and Freeman, M. P.: A technique for accurately determining the cusp region polar cap boundary using SuperDARN HF radar measurements, Ann. Geophys., 21, 983-996, 2003.

Chisham, G., Freeman, M. P., and Sotirelis, T.: A statistical comparison of SuperDARN spectral width boundaries and DMSP particle precipitation boundaries in the nightside ionosphere, Geophys. Res. Lett., 31, doi: 10.1029/2003GL019074, 2004a.

Chisham, G. and Freeman, M. P.: An investigation of high latitudinal transitions in the SuperDARN Doppler spectral width parameter at different magnetic local times, Ann. Geophys., in press, 2004b.

Cowley, S. W. H. and Lockwood, M.: Excitation and decay of solar wind-driven flows in the magnetosphere-ionosphere system, Ann. Geophys., 10, 103-115, 1992.

Cowley, S. W. H. and Lockwood, M.: Time-dependent flows in the coupled solar wind-magnetosphere-ionosphere system, Adv. Space. Res., 18, 141-150, 1996.

Dudeney, J. R., Rodger, A. S., Freeman, M. P., Pickett, J., Scudder, J., Sofko, G., and Lester, M.: The nightside ionospheric response to IMF By changes, Geophys. Res. Lett, 25, 2601-26041, 1998.

Dungey, J. W.: Interplanetary field and the auroral zones, Phys. Res. Lett., 6, 47-48, 1961.

Evans, L. C. and Stone, E. C.: Electron polar cap and the boundary of open geomagnetic field lines, J. Geophys. Res., 77, 55805585, 1972.

Feldstein, Y. I. and Starkov, G. V.: Dynamics of auroral belt and geomagnetic disturbances, Planet. Space Sci., 15, 209-229, 1967.

Frank, L. A. and Ackerson, K. L.: Observations of charged particle precipitation into the auroral zone, J. Geophys. Res., 76, 36123643, 1971.

Frank, L. A. and Craven, J. D.: Imaging results from Dynamics Explorer 1, Rev. Geophys., 26, 249-283, 1988.

Frey, H. U., Mende, S. B., Carlson, C.W., Gérard, J.-C., Hubert, B., Spann, J., Gladstone, R., and Immel, T. J.: The electron and 
proton aurora as seen by IMAGE-FUV and FAST, Geophys. Res. Lett, 28, 1135-1138, 2001.

Galperin, Y. I. and Feldstein, Y. I.: Auroral luminosity and its relationship to magnetospheric plasma domains, in: Auroral Physics, edited by Meng, C.-I., Rycroft, M. J., and Frank, L. A., Cambridge University Press, New York, 1207-222, 1991.

Greenwald, R. A., Baker, K. B., Dudeney, J. R., Pinnock, M., Jones, T. B., Thomas, E. C., Villain, J.-P., Cerisier, J.-C., Senior, C., Hanuise, C., Hunsucker, R. D., Sofko, G., Koehler, J., Nielsen, E., Pellinen, R., Walker, A. D. M., Sato, N., and Yamagishi, H.: Darn/SuperDARN: a global view of the dynamics of highlatitude convection, Space Sci. Rev, 71, 761-796, 1995.

Hardy, D. A., Schmitt, L. K., Gussenhoven, M. S., Marshall, F. J., Yeh, H. C., and Schumaker, T. L., Huber, A. and Pantazis, J.: Precipitating electron and ion detectors (SSJ/4) for the block 5D/Flights 6-10 DMSP satellites: calibration and data presentation, Rep. AFGL-TR-84-0317, Air Force Geophys. Lab., Hanscom AFB, Mass., 1984.

Hubert, B., Gérard, J.-C., Evans, D. S., Meurant, M., Mende, S. B., Frey, H. U., and Immel, T. J.: Total electron and proton energy input during auroral substorms: Remote sensing with IMAGEFUV, J. Geophys. Res., 107, 10.1029/2001JA009229, 2002.

Johnstone, A. D., Alsop, C., Burge, S., Carter, P. J., Coates, A. J., Coker, A. J., Fazakerley, A. N., Grande, M., Gowen, R. A., Gurgiolo, C., Hancock, B. K., Narheim, B., Preece, A., Sheather, P. H., Winningham, J. D., and Woodliffe, R. D.: PEACE: A Plasma Elctron And Current Instrument, Space Sci. Rev., 79, 351-398, 1997.

Kauristie, K., Weygand, J., Pulkkinen, T. I., Murphree, J. S., and Newell, P. T.: Size of the auroral oval: UV ovals and precipitation boundaries compared, J. Geophys. Res., 104, 2321-2331, 1999.

Khan, H. and Cowley, S. W. H.: Observations of the response time of high latitude ionospheric convection to variations in the interplanetary magnetic field using EISCAT and IMP-8 data, Ann. Geophys., 17, 1306-1335, 1999.

Lester, M., Milan, S. E., Besser, V., and Smith, R.: A case study of $\mathrm{HF}$ radar backscatter and $630.0 \mathrm{~nm}$ auroral emission, Ann. Geophys., 19, 327-340, 2001.

Lewis, R. V., Freeman, M. P., Rodger, A. S., Reeves, G. D., and Milling, D. K.: The electric field response to the growth phase and expansion phase onset of a small isolated substorm, Ann. Geophys., 15, 289-299, 1997.

Lewis, R. V., Freeman, M. P., and Reeves, G. D.: The relationship of HF radar backscatter to the accumulation of open magnetic flux prior to substorm onset, J. Geophys. Res, 103, 26 613-26,619, 1998.

Lockwood, M.: Relationship of auroral precipitationsto the openclosed sepratrix and the pattern of convective flow, J. Geophys. Res, 102, 17475-17487, 1997.

Lockwood, M., Carlson Jr., H. C. and Sandholt, P. E.: Implications of the altitude of transient 630-nm dayside auroral emissions, J. Geophys. Res., 98, 15 571-15 587, 1993.

McComas, D. J., Bame, S. J., Barker, P., Feldman, W. C., Phillips, J. L., Riley, P., and Griffee, J. W.: Solar Wind Electron Proton Alpha Monitor (SWEPAM) for the Advanced Composition Explorer, Space Sci. Rev., 86, 563-612, 1998.

Mende, S. B., Heetderks, H., Frey, H. U., Lampton, M., Geller, S. P., Habraken, S., Renotte, E., Jamar, C., Rochus, P., Spann, J., Fuselier, S. A., Gerard, J.-C., Gladstone, R., Murphree, S., and Cogger, L.: Far ultraviolet imaging from the IMAGE spacecraft: 1. System design, Space Sci. Rev. 91, 243-270, 2000a.

Mende, S. B., Heetderks, H., Frey, H. U., Lampton, M., Geller, S.
P., Abiad, R., Siegmund, O., Tremsin, A. S., Spann, J., Dougani, H., Fuselier, S. A., Magoncelli, A. L., Bumala, M. B., Murphree, S., Trondsen, T.: Far ultraviolet imaging from the IMAGE spacecraft: 2. Wideband FUV imaging, Space Sci. Rev., 91, 271-285, 2000b.

Menk, F. W., Fraser, B. J., Hansen, H. J., Newell, P. T., Meng, C.-I., and Morris, R. J.: Identification of magnetospheric cusp and cleft ucing Pc1-2 ULF pulsations, J. Atmos. Terr. Phys., 54, 10211042, 1992.

Milan, S. E. and Lester, M.: Interhemispheric differences in the HF radar signature of the cusp region: A review through study of a case example, Adv. Polar Upper Atmos. Res., 15, 159-177, 2001.

Milan, S. E., Lester, M., Cowley, S. W. H., Oksavik, K., Brittnacher, M., Greenwald, R. A., Sofko, G., and Villain, J.-P.: Variations in polar cap area during two substorm cycles, Ann. Geophys., 21, 1121-1140, 2003.

Newell, P. T.: Reconsidering the inverted-V particle signature: Relative frequency of large-scale electron acceleration events, J. Geophys. Res., 105, 15 779-15 794, 2000.

Newell, P. T. and Meng, C.-I.: The cusp and cleft/boundary layer: Low-altitude identification and statistical local time variations, J. Geophys. Rev., 93, 14 549-14 556, 1988.

Oksavik, K., Sørras, F., Moen, J., and Burke, W. J.: Optical and particle signatures of magnetospheric boundary layers near magnetic noon: Satellite and ground-based observations, J. Geophys. Res., 105, 27 555-27 568, 2000.

Owen, C. J., Fazakerley, A. N., Carter, P. J., Coates, A. J., Krauklis, I. C., Szita, S., Taylor, M. G. G. T., Travnicek, P., Watson, G., Wilson, R. J., Balogh, A., and Dunlop, M. W.: Cluster PEACE observations of electrons during magnetospheric flux transfer events, Ann. Geophys., 19, 1509-1522, 2001.

Rème, H., Bosqued, J.-M., Sauvaud, J. A., Cros, A., Dandouras, J., Aoustin, C., Bouyssou, J., Camus, Th., Cuvilo, J., Martz, C., M'Edale, J. L., Perrier, H., Romefort, D., Rouzaud, J., d’Uston, C., Möbius, E., Crocker, K., Granoff, M., Kistler, L. M., Popecki, M., Hovestadt, D., Klecker, B., Paschmann, G., Scholer, M., Carlson, C. W., Curtis, D. W., Lin, R. P., McFadden, J. P., Formisano, V., Amata, E., Bavassano-Cattaneo, M. B., Baldetti, P., Belluci, G., Bruno, R., Chionchio, G., Di Lellis, A., Shelley, E. G., Ghielmetti, A. G., Lennartsson, W., Korth, A., Rosenbauer, H., Lundin, R., Olsen, S., Parks, G. K., Mccarthy, M., and Balsiger, H.: The Cluster Ion Spectrometry (CIS) Experiment, Space Sci. Rev., 79, 303-350, 1997.

Rème H., Aoustin, C., Bosqued, J.-M., Dandouras, I., Lavraud, B., Sauvaud, J. A., Barthe, A., Bouyssou, J., Camus, Th., CoeurJoly, O., Cros, A., Cuvilo, J., Ducay, F., Garbarowitz, Y., Medale, J. L., Penou, E., Perrier, H., Romefort, D., Rouzaud, J., Vallat, C., Alcaydé, D., Jacquey, C., Mazelle, C., d'Uston, C., Möbius, E., Kistler, L. M., Crocker, K., Granoff, M., Mouikis, C., Popecki, M., Vosbury, M., Klecker, B., Hovestadt, D., Kucharek, H., Kuenneth, E., Paschmann, G., Scholer, M., Sckopke, N., Seidenschwang, E., Carlson, C. W., Curtis, D. W., Ingraham, C., Lin, R. P., McFadden, J. P., Parks, G. K., Phan, T., Formisano, V., Amata, E., Bavassano-Cattaneo, M. B., Baldetti, P., Bruno, R., Chionchio, G., Di Lellis, A., Marcucci, M. F., Pallocchia, G., Korth, A., Daly, P. W., Graeve, B., Rosenbauer, H., Vasyliunas, V., McCarthy, M., Wilber, M., Eliasson, L., Lundin, R., Olsen, S., Shelley, E. G., Fuselier, S., Ghielmetti, A. G., Lennartsson, W., Escoubet, C. P., Balsiger, H., Friedel, R., Cao, J.-B., Kovrazhkin, R. A., Papamastorakis, I., Pellat, R., Scudder, J., and Sonnerup, B.:First multispacecraft ion measurements in and near the Earth's 
magnetosphere with the identical Cluster ion spectrometry (CIS) experiment, Ann. Geophys., 19, 1303-1354, 2001.

Rodger, A. S.: Ground-based imaging of magnetospheric boundaries, Adv. Space Res, 25, 1461-1470, 2000.

Rostoker, G., Samson, J. C., Creutzberg, F., Hughes, T. J., McDiarmid, D. R., McNamara, A. G., Jones, A. V., Wallis, D. D., Cogger ,L. L.: CANOPUS - a ground-based instrument array for remote-sensing the high-latitude ionosphere during the ISTP/GGS program, Space Sci. Rev., 71, 743-760, 1995.

Sergeev, V. A., Malkov, M., and Mursula, K.: Testing the isotropic boundary algorithm method to evaluate the magnetic field configuration in the tail, J. Geophys. Res., 98, 7609-7620, 1993.

Siscoe, G. L. and Huang, T. S.: Polar cap inflation and deflation, J. Geophys. Res., 90, 543-547, 1985.

Smith, C. W., Acu na, M. H., Burlaga, L. F., L'Heureux, J., Ness, N. F., and Scheifele, J.: The ACE Magnetic Fields Experiment, Space Sci. Rev., 86, 613-632, 1998.
Stone, E. C., Frandsen, A. M., Mewaldt, R. A., Christian, E. R., Marglies, D., Ormes, J. F., and Snow, F.: The Advanced Composition Explorer, Space Sci. Rev., 86, 1-22, 1998.

Tsyganenko, N. A.: Modeling the Earth's magnetospheric magnetic field within a realistic magnetopause, J. Geophys. Res., 100, 5599-5612, 1995.

Tsyganenko, N. A.: Effects of the solar wind conditions on the global magnetospheric configuration as deduced from data-based field, in: Proc. 3rd Internat. Conf. on Substorms (ICS-3), ESA SP-389, 181-185, 1996.

Woodfield, E. E.: An inter-hemispheric, statistical study of nightside spectral width distributions from coherent HF scatter radars, Ann. Geophys., 20, 1921-1934, 2002. 